Note: This is a pre-copy-editing, author-produced PDF of an article accepted for publication in Journal of Psychiatric and Mental Health Nursing following peer review. The definitive publisher-authenticated version [McLaughlin DF and McKenna $\mathrm{H}$ (2000) The perceptions and aspirations illicit drug users hold toward health care staff and the care they receive, Journal of Psychiatric and Mental Health Nursing, 7, 435-441] is available online at http://www3.interscience. wiley.com/journal/118506499/toc

\title{
The perceptions and aspirations illicit drug users hold toward health care staff and the care they receive
}

\author{
D. F. MCLAUGHLIN1 and H. MCKENNA
}

\author{
Journal of Psychiatric and Mental Health Nursing 7, 435-441 \\ Published by Blackwell Science
}

Over the 30 years of conflict, Northern Ireland escaped the worst excess of illegal drug trafficking and usage. However, the recent 'peace dividend' has brought with it an unprecedented rise in the availability and use of illicit drugs. With this, new problems and pressures have been brought to bear on the health service. The literature would suggest that drug users are loathed and feared by health care staff. Staff will also admit to be lacking in the knowledge and skills necessary for the delivery of appropriate support and treatment for this client group. Further, the literature has little to offer on the experiences and aspirations of drug users in relation to their treatment and the staff who care for them. In order to understand the drug users' experiences of health care and health staff, focus group methodology was employed to obtain qualitative data. A total of 20 illicit drug users from across Northern Ireland took part. Supporting the literature, all had experienced 'care' that they felt was filled with judgement, hostility and loathing. They recognized clearly the challenge they pose to health care staff. These findings indicate that there is obvious dissonance between those tasked to care for drug users and drug users themselves, with little respect being shown on either side. Results suggest that action needs to be taken to address the deficits in the knowledge, skills and values of health care professionals in relation to illicit drug users. The findings will be of interest to service providers within and outside the United Kingdom.

Keywords: addiction, attitudes, drug abuse, health care staff, illicit drug users, perceptions

\section{Introduction}

Over the 30 years of conflict, Northern Ireland escaped the worst excesses of illegal drug trafficking and usage. Since the first 'cease-fire' in 1994, Northern Ireland has witnessed a dramatic and unprecedented rise in the availability of illicit drugs (RUC 1998). This increased availability reflects rising consumption of these drugs in the province (Craig 1997). Health professionals are being helped in the process of coming to terms with this alarming and rapidly developing situation. The DHSS (1999) published Drug Misuse and Dependency Guidelines on Clinical Management. This publication indicates clearly the seriousness with which the health service is taking the growing illicit drug problem. It also calls for initiatives to address the low levels of staff knowledge and skills in caring for a person with illicit drug-related difficulties.

In recent years, there have been large drugs seizures in Northern Ireland (RUC 1998). It could be suggested that this reflects increased trafficking of these drugs, which in turn is an attempt to meet the growing demand for illicit drugs. A joint study between the Health Promotion Agency for Northern Ireland and the World Health Organisation (HPANI 1995) investigated drug use in the province. This study, using a large representative sample of fifth form secondary school children (15-16 years), showed an upward trend in availability, use and continued use of illicit drugs. Craig (1997) validated the results of this research when she surveyed a large number of sixth formers (16-17 years) within the province. She also found that there was a rising trend in the availability, use and prolonged use of illicit drugs. 
The Northern Ireland Statistical Information Bulletin (DHSS 1997) reflects this trend. This is a DHSS record of people considered to have a serious dependency on certain illicit drugs, as reported by their medical practitioners. The numbers reported are not large, but the trend is rising steeply and represents a very real cause for concern. It is evident that more individuals are using illicit drugs, and, more importantly, they are developing dependencies on these drugs. This offers a new challenge for the health care providers in the province.

Unfortunately, there is little evidence to indicate how prepared local health professionals are to meet this challenge and how they react to illicit drug users.

A rigorous search strategy was employed to uncover national and international theoretical and research literature pertaining to the topic. As well as hand searching, a trawl of Medline, Cinahl, Psychlit, and the Cochrane and Centre for Reviews and Dissemination databases was undertaken, using the following key words: 'drug abuse', 'drug misuse', 'addiction' and 'care'. While a large number of hits were identified, attention was directed at those sources which pertained to the perceptions that addicted clients and health professionals had of each other.

The review noted that in relation to the care of drug users, a great deal of the available literature attempts to understand and explore the views of health care staff (Greenwood 1992, Melby et al. 1992, Carroll 1996). Often, these surveys are small in scope and focus upon the professionals' views of drug users' needs, with little attention being paid to the drug users' own views (McLaughlin \& Long 1996). However, the evidence from national and international studies is clear with regard to the views of health care staff on users of illicit drugs. In the main, findings over the past three decades seem to indicate that illicit drug users are often loathed and feared by health care staff (Romney \& Bynner 1972; Cohen et al. 1992, Melby et al. 1992, Blank \& Nelles 1993, Carroll 1996, McLaughlin \& Long 1996). Staff will also admit to lacking the relevant knowledge, skills and values for the delivery of appropriate care and treatment for this client group (Soverow et al. 1972, Beauvais et al. 1991, Gorman \& Morris 1991, King 1997, King et al. 1998).

Within the literature, there is very little data on the experiences and aspirations of illicit drug users in relation to their treatment and the staff who care for them (Gossop et al. 1982, Bennett \& Wright 1986; Morrison \& Plant 1990, Telfer \& Clulow 1990, Rohrer et al. 1992, Hindler et al. 1996).

Furthermore, the approaches adopted are of a quantitative nature, employing questionnaires or structured interviews (Gossop et al. 1982, Bennett \& Wright 1986, Morrison \& Plant 1990, Telfer \& Clulow 1990). The use of a questionnaire with this client group may not be justified, as the present study would suggest that a quarter do not posses any basic educational qualifications and therefore literacy levels are a real concern. To attempt to develop helping strategies for these individuals without first understanding their experiences and aspirations would be omitting a fundamental element in the process of delivering effective care.

To summarize the literature review, there is strong evidence to suggest that users of illicit drugs and their health service carers have problems with how they perceive and communicate with each other. In the main, findings would indicate that the recipients of care are treated very badly or ignored by health professionals. This may be due to the admitted lack of knowledge and skill in dealing with the problems that illicit drug users bring to services. There is a dearth of research on these issues from the drug users' perspective. This present study aims to address this oversight.

\section{Method}

The objectives of this study were to collect data from illicit drug users, exploring their perceptions and aspirations in relation to their health care and health care staff, and to analyse the data for recurring themes and important issues. Careful consideration was given to the most suitable manner of collecting this sensitive information. It was decided not to interview individuals on a one-to-one basis, as this may have been perceived as threatening and inhibiting by the interviewee. Krueger (1994) reports that, because of painful consequences, people learn early to withhold information. 
Considering the client group in the present study, this suggests that individuals may not be forthright about their perceptions and aspirations. Further, organizing a series of one-to-one interviews would be difficult logistically and therefore not the most efficient use of time and resources.

It was decided to use the qualitative focus group method of data collection. Yalom (1985) reports that groups encourage a sense of being together, of mutual support and, by their very nature, they promote discourse. A focus group has been defined as a carefully planned discussion designed to obtain perceptions on a defined area of interest in a permissive, non-threatening environment (Krueger 1994). He argues that focus groups can provide information about the feelings and attitudes of participants. Further, he found that people will tend to disclose more about themselves to others who resemble them in various ways. It was hoped that if brought together in a nonthreatening and comfortable environment, a group of drug users would be able to talk freely about their experiences.

\section{Sample selection}

As with any group work, a great deal of preparation went into organising the focus groups. Firstly, selection criteria for group participation were drawn up:

- The group will be made up of people who have used illicit drugs, as defined in the Misuse of Drugs Act 1971.

- The minimum age for participants will be 18 years of age.

- The drug user will be in the process of addressing or have addressed his/her dependency problem.

- The person will have approached a health professional seeking help for his/her drug problem.

- Each participant will be a volunteer and no pressure will be exerted to encourage participation.

- No group member will be known to the author, either clinically or personally.

- The participant is agreeable to the focus group being audio-taped.

\section{Pilot study}

A pilot study took place with a small group of illicit drug users. As a result of the findings, some of the questions were slightly reworded. Another important issue was the timing of the focus groups.

Discussion within the pilot showed that the most appropriate time to hold focus groups was during the evenings and at weekends.

\section{Research instrument}

A number of key questions were formulated from the literature to stimulate the group's discussion and to set its agenda. As mentioned above, these were altered slightly as a result of the pilot study.

Krueger (1994) reports that it is crucial for a successful focus group that questions are open-ended, carefully thought through and asked in an order that will appear to the group members as natural and logical. He states that the focus group is concerned with what people did rather than what they would like to do. Therefore, questions are set in the 'there and then' instead of the 'here and now': this encourages participants to talk of actual events. The following open questions were posed:

- Think back to when you made a decision to do something about your use of drugs; what did you actually do?

- Did you ever approach a health professional for help about your drug problem?

-What was their response?

- Were there any differences in their response, when you sought help about a problem that was not drug-related?

-What experiences have you had with specialist addiction services?

- Have you noted any differences between specialist addiction services and the usual health services?

- How can the health service and its personnel offer better care for drug users?

- Are there any other issues you would like to discuss?

\section{Ethical issues}

There were several ethical considerations in relation to this study. These centred on the fact that the issues to be discussed and audio-taped were often of an illegal nature. Potentially this could have had serious consequences for the researcher, those associated with the research and those people 
taking part in the focus groups. Confidentiality was essential for the protection of the participants and the researcher; therefore, only verbal rather than written consent was sought. The participants were fully informed of the nature and purpose of the research prior to obtaining their consent. Formal ethical approval was also sought and given by the University of Ulster's Ethics Committee.

\section{Access}

Treatment agencies and support groups across the statutory and voluntary sector were approached and asked for their assistance in the recruitment of volunteers. In total, seven focus groups took place with 20 individuals participating. Considering the difficulty of accessing this client group, 20 was thought to be an acceptable sample size. Krueger (1994) stressed that a researcher using a focus group approach should be concerned with how appropriate the participants are to the topic being researched. They should be selected on issues of similarity and relevance rather than availability. At the beginning of each focus group, participants were asked to complete a brief questionnaire pertaining to their biographical details.

\section{The data collection process}

After the treatment agency or support groups informed the researcher of potential participants, their consent to meet was obtained. A meeting was organized, taking into account a venue, date and time that would be suitable to the participants. Careful attention was paid to the physical environment to ensure comfort, safety and privacy. Those present were asked if they would like to join the focus group discussion. Those electing to stay were then asked to give their verbal consent to take part in the research. It was made clear that any participant who wished to withdraw their consent was free to do so at any time. To aid clear recording of the discussion, the audio tape recorder was placed in the centre of the focus group. No-one present refused to be involved in the focus groups.

The researcher began the discussion by welcoming all present and thanking them for their attendance. A general chat about how the focus group would function allowed some of the expected anxiety to dissipate. When all the questions were addressed by the focus group to the researchers' satisfaction, the participants were given an opportunity to discuss any issues they felt important to the subject area. When no further comments or queries were offered, the focus group was brought to a close.

\section{Data analysis}

In qualitative research, data analysis refers to a range of activities during which data is ordered, categorized and interpreted. A content analysis approach was used, defined by Polit \& Hungler (1995) as a procedure for analysing verbal communication in a systematic and objective fashion. Miles \& Huberman (1984) state that qualitative data analysis is a cyclical and interactive procedure involving the reduction and display of and a developed understanding from the data. The tapes were transcribed to aid careful examination for emerging issues and themes. Over a period of weeks, the tapes were listened to and the transcripts were read many times. Throughout this process, the attempt to develop understanding and draw conclusions from the data continued. The entire process was overseen by two researchers experienced in this approach to analysis (Cutcliffe \& McKenna 1999). Many distinct themes and issues emerged from the data. These emerged again and again from different participants in different groups at different times and locations. However, while the themes and issues were distinct, they would often link and intertwine with one and other.

\section{Results}

\section{Demographic details}

Of the twenty people who took part, thirteen participants were recruited from the voluntary sector, with the remainder drawn from the statutory services. Seven were female $(35 \%)$ and thirteen male. This gender profile differs from data from the Regional Drug Misuse Database (DHSS 1999), which reports a quarter of those presenting for drug treatment would be female. Of the participants, twelve were 30 years or under, with ages ranging from 18-56 years. The mean age was 31 . Only two participants were in full time employment, fourteen were in receipt of social welfare benefit; the remainder were in full time education. In relation to marital status, thirteen were single, two were married and the 
remainder either divorced or separated. A quarter of participants had no basic educational qualifications.

\section{Themes}

The dominant theme to arise from all the focus groups and each participant taking part was that of being 'cared for'. They referred to the care and help they received in relation to their drug problems. This care was often associated strongly with specialist addiction staff. Eighteen related high quality care and treatment provided by such staff. Only one participant spoke negatively of his experiences at the hands of specialist addiction staff. One young man gave an example of being 'cared for':

'That's the main thing that gets me, they listen to you, they comprehend what you are talking about and they can give you some sort of resolve for it' (Participant 11, Focus Group 4).

High quality care was very important to the study's participants; sixteen offered insights into their views of how a person with illicit drug problems should be cared for. One man summed up his views of 'ideal care' as follows:

'What nurses and doctors should do is nurture people; that's worked for me, it worked for me. It made me stop, it made me look at myself and stop and think, okay, I am worth a bit more and am only committing suicide here by using all the time' (Participant 01, Focus Group 1).

Another recurring and dominant theme was that of health staff being perceived as uncaring. Sixteen participants discussed their experiences in relation to this theme. These experiences concerned the care and treatment provided by generalists rather than specialist addiction practitioners. One man stated:

'As I recall I went to see my GP shortly before I came in here, I discussed my problems with him but he didn't say much he didn't even suggest any form of help let alone offer help himself or offer to refer me to here or anywhere else for that matter' (Participant 07, Focus Group 2).

Another strong theme to emerge was the recognition of health professionals' lack of education, training, skills and knowledge of drug problems. All participants related experiences when they could see these deficits in non-specialist health care staff. Illicit drug users have often exploited this lack of knowledge and understanding. Three-quarters $(n=15)$ related how they used these deficits to manipulate staff in a variety of ways, most frequently to obtain prescriptions. One young woman gave a graphic example of how she could manipulate situations. This extract highlighted the very real challenge illicit drug users pose to the practitioners who care for them:

But I mean the likes of me, now, if I was going in, I would be able to put on a great old show like you know, I can't sleep and all and my nerves are away and I'm afraid to go outside [said in altered voice], I don't know and nobody are mind readers but I do think they should know a wee bit more about it, because drug addicts can be very, very cunning when they want to be, you know we can' (Participant 13, Focus Group 4).

Sixty percent $(n=12)$ of participants questioned the motives of their general practitioner (GP) in the prescription of drugs to them. It would seem that some of the prescriptions they received were nonclinical. One man compared his GP to a drug pusher:

'he ended up sort of pushing it my way'(Participant 09, Focus Group 3).

For another young man, his GP had evolved into a supplier of drugs; he summed it up as follows: 
'They become your pharmacists, that's all a doctor has become to me in the end. I have heard loads of people talking about their doctors and having conversations with their doctors and they would ask them how are you getting on and how's life, I have never met a doctor like it but they are just a pharmacist to me and that's all' (Participant 11, Focus Group 4).

This challenging behaviour was recognised by thirteen participants as being very difficult for health care staff to deal with. Within some of the groups, a high degree of empathy was evident for health professionals whose job it is to care for illicit drug users. Six participants also admitted to telling lies and withholding vital information from health care staff. One young man described some of his experiences for his GP:

'And he doesn't know, God love him [GP], he doesn't know they're going down and using him to get what they need for a week, about a weeks supply or how long it takes to build up some more money and then back onto the gear, you know what I mean, you know I have done it myself, it was down to the fact, look I went out, I need help, he gave me these tablets, there you go get off it, take these you will be all right do you know what I mean ... the tablets were all right and I was going back for more. I found myself getting repeat prescriptions going out telling more lies' (Participant 15, Focus Group 5).

All participants mentioned their GP during the focus groups. While a small minority reported positive experiences, sixteen related difficulties with this professional group. All thought GPs needed more education in the care of illicit drug users. Fifty-five percent $(n=11)$ did not expect the GP to be an expert in the field, but to be able to identify the problem and make a referral to a specialist addiction service. One man summed this up:

'I think the role they [GPs] actually need to fill, is to be aware of their own limitations and to be able to put you in touch with people who can help and to be aware that these avenues/options do exist'(Participant 9, Focus Group 3).

\section{Discussion}

Over the last three decades, a common theme emanating from the research literature is that health care staff abhor and dread illicit drug users (Romney \& Bynner 1972, Cohen et al. 1992, Melby et al. 1992, Blank \& Nelles 1993, Carroll 1996, McLaughlin \& Long 1996). This was also supported from findings from this present study: participants perceived this loathing for them to exist in the health service. The call for humanized and individualized care has been made in the literature (Rohrer et al. 1992, McLaughlin \& Long 1996). This was also a very clear message to emanate from this research.

Findings also show that providing care and treatment to this group of clients can be extremely challenging. Three-quarters of those participating admitted to manipulating health care staff and nearly a third reported lying and withholding information. This supports and confirms the work of Greenwood (1992), Forrester \& Murphy (1992) and Rassool (1993). They identified very real difficulties illicit drug users pose to health care workers attempting to give care to them.

All the participants taking part in the study perceived that health professionals had a lack of knowledge and skill in relation to the care of illicit drug users. This has been identified on numerous occasions in previous studies (Soverow et al. 1972, Beauvais et al. 1991, Gorman \& Morris 1991, King 1997, King et al. 1998).

Participants admitted that they often lied, manipulated and withheld information from professional carers. They recognised the difficulties they posed to health care staff and expressed empathy for the staff charged with their care. This tendency for illicit drug users to empathize with staff was a theme not found within the published literature. Furthermore, the concern expressed by participants regarding the uncaring approach taken by many staff toward them was also absent from the accessed literature. 


\section{Limitations}

The most obvious concern is the size of the sample taking part in the focus groups. The number of people using illicit drugs is growing, yet those willing to speak about it to researchers on this occasion were relatively small in number. This stems from their behaviour being an illegal activity and the open hostility illicit drug users face at every level of society. While it would have been desirable to interview larger numbers, 20 participants from a hard-to-reach and often very secretive group of people entailed a lot of effort and perseverance. However, the quality of the participants' contribution was good. A potential drawback of the group approach is possible domination by one or two individuals and their contribution skewing the data. While this was a concern, the authors' many years of experience in group-work ensured that it did not occur. By the very nature of the study, no attempt is made to generalize the findings to other individuals or settings outside those of the present study.

\section{Rigour of the study}

Lincoln \& Guba (1985) point out that the psychometric properties of validity and reliability are positivistic in origin and not appropriate criteria for judging the relevance and rigour of qualitative research approaches. Rather they identify credibility, auditability and confirmability as relevant to this research paradigm. In the present study, credibility was achieved by undertaking a well-designed search of the extant literature databases. The questions, prompts and probes used in the focus groups emanated from the literature, much of which was written by experts in the field (Telfer \& Clulow 1990, Beauvais et al. 1991, Gorman \& Morris 1991, Cohen et al. 1992, Rohrer et al. 1992, Blank \& Nelles 1993, Rassool 1993, Carroll 1996, Hindler et al. 1996, King et al. 1998).

The focus group approach was justified in the methods section and the organizational, practical and ethical guidelines for running such groups were taken from the well-regarded work of Krueger (1994). As a result, it is possible for readers and other researchers to follow a methodological audit trail. Most of the findings were confirmed through comparing them with those from other well-designed national and international studies. Confirmation of the emerging themes was also achieved through noting that the same issues arose again and again from different participants in different groups at different times and locations.

\section{Conclusions}

The findings of this study support those of previous studies and uncover new information not found in the extant accessed literature. The experiences and aspiration of illicit drug users fills an important omission in our understanding of this group of clients. A lot of important issues have been raised for health care staff in relation to giving effective care to this client group. The following conclusions pertain to the participants in the present study:

- People that use illicit drugs crave care and treatment that is knowledgeable, caring and humanistic.

- Illicit drug users recognize the real challenges they pose to health care professionals who are attempting to care for and treat them.

- The perception of being loathed by practitioners is very clear to those taking part in this study.

- Illicit drug users clearly identify the deficits in professionals' knowledge and skills in relation to the care and treatment of users and their problems.

- Illicit drug users recognize and respond positively to care and treatment from staff that are knowledgeable, understanding, caring and skilled.

\section{Recommendations}

What is very clear is that more rather than fewer illicit drug users will be coming into contact with health professionals. Increasingly, nurses in acute and primary care roles will be caring for such individuals. This will be especially the case for community psychiatric nurses. These practitioners must address radically the current 'standard' of their knowledge, skills and care. While generalization is not attempted, the lessons are transferable to national and international colleagues. The people who use illicit drugs can be challenging in the extreme to those trying to help them. Yet they are often cared, lonely and isolated, in need of treatment and care, and all too often they receive judgement and hostility. It is recommended that this study be replicated and the lessons learned used to effect 
change in caring for this group of people. An enhanced educational package for health care staff should be formulated. This package should cover some basic needs in relation to knowledge and understanding of the issues raised by illicit drug use.

\section{Acknowledgments}

A sincere thank you is extended to all the people who took part in the focus groups. Also to the staff from the following organizations who helped so much: Homefirst Community Addiction Service, Carlisle House, The Northlands Centre, Shaftsbury Square Hospital, and the Dunlewey Substance Advice Centre, and the DHSS through the Research Studentship Award and NBNI/ An Bord Altranais for their support via an All-Ireland Research Fellowship.

\section{References}

Beauvais F., Spooner S. \& Oetting E.R. (1991) The role of the psychologist on the drug user treatment team. International Journal of the Addictions 26, 1137-1158.

Bennett T. \& Wright R. (1986) Opioid users attitudes towards and use of NHS clinics, general practitioners and private doctors. British Journal of Addiction 81, 757-763.

Blank M. \& Nelles B. (1993) Education and training GPs in the management and treatment of drug users. International Journal of Drug Policy 4, 49-54.

Carroll J. (1996) Attitudes to drug users according to age of staff. Professional Nurse 11, 401-404.

Cohen J., Schamroth A., Nazareth I., Johnson M. \& Graham S. \& Thomson D. (1992) Problem drug use in a central London general practice. British Medical Journal 304, 1158-1160.

Craig J. (1997) Almost Adult. Northern Ireland Statistics and Research Agency, Belfast.

Cutcliffe J.R. \& McKenna H.P. (1999) Establishing the credibility of qualitative research findings: the plot thickens. Journal of Advanced Nursing 39, 374-380.

DHSS (1997) Northern Ireland Drug Addicts Statistical Information Bulletin. Department of Health \& Social Services, Belfast.

DHSS (1999) Drug Misuse and Dependence: Guidelines on Clinical Management. Department of Health \& Social Services, Belfast.

Forrester D.A. \& Murphy P.A. (1992) Nurses attitudes towards patients with AIDS and AIDS-related risk factors. Journal of Advanced Nursing 17, 1260-1266.

Gorman M. \& Morris A. (1991) Developing clinical expertise in the care of addicted patients in acute care settings. Journal of Professional Nursing 7, 246-254.

Gossop M., Eiser J.R. \& Ward E. (1982) The addict's perception of their own drug-taking: implications for the treatment of drug dependence. Addictive Behaviours 7, 189-194.

Greenwood J. (1992) Unpopular patients: GP's attitudes to drug users. Drug Link Jul/August, 8-10.

Hindler C., King M., Nazareth I., Cohen J., Farmer R. \& Gerada C. (1996) Characteristics of drug misusers and their perceptions of general practitioner care. British Journal of General Practice 46, 149-152.

HPANI (1995) The Health Behaviour of School Children in Northern Ireland. Health Promotion Agency for Northern Ireland, Belfast.

King L. (1997) Structured GP liaison for substance misuse. Nursing Times 93, 30-31.

King M., Hindler C., Nazareth I., Farmer R., Gerada C. \& Cohen J. (1998) A controlled evaluation of small-group education of general practitioners in the management of drug users. British Journal of General Practice 48, 1159-1160.

Krueger R.A. (1994) Focus Groups: A Practical Guide for Applied Research, 2nd edn. Sage, London. Lincoln Y.S. \& Guba E.G. (1985) Naturalistic Inquiry. Sage, London.

McLaughlin D.F. \& Long A. (1996) An extended literature review of health professionals' perceptions of illicit drugs and their clients who use them. Journal of Psychiatric and Mental Health Nursing 3, 283-288.

Melby V., Boore J.R.P. \& Murray M. (1992) Acquired immunodeficiency syndrome: knowledge and attitudes of nurses in Northern Ireland. Journal of Advanced Nursing 17, 1068-1077.

Miles M.B. \& Huberman A.M. (1984) Qualitative Nursing Research. A Contemporary Dialogue. Sage, London.

Morrison V. \& Plant P. (1990) Drug problems and patterns of service use amongst illicit drug users in Edinburgh. British Journal of Addiction 85, 547-554. 
Polit D.F. \& Hungler B.P. (1995) Nursing Research Principles and Methods, 5th edn. J.B. Lippincott, Philadelphia, PA.

Rassool G.H. (1993) Nursing and substance misuse: responding to challenge. Journal of Advanced Nursing 18, 1401-1407.

Rohrer G.E., Thomas M. \& Yasenchak A.B. (1992) Client perceptions of the ideal addictions counsellor. International Journal of the Addictions 27, 727-733.

Romney D. \& Bynner J. (1972) Drug addicts as perceived by hospital staff. British Journal of Social and Clinical Psychology 11, 20-34.

RUC (1998) Chief Constables' Annual Report 1997. Royal Ulster Constabulary, London.

Soverow G., Rosenberg C.M. \& Ferneau E. (1972) Attitudes towards drug and alcohol addiction: patients and staff. British Journal of Addiction 67, 195-198.

Telfer I. \& Clulow C. (1990) Heroin misusers: what they think of their general practitioners. British Journal of Addiction 85, 137-140.

Yalom I.D. (1985) The Theory and Practice of Group Psychotherapy, 3rd edn. Basic Books, New York. 